\title{
Study of radiological findings in papilledema
}

\author{
Meena $\mathbf{V}^{1}$, Sharma $\mathbf{U}^{2}$ \\ ${ }^{1}$ Dr. Vandana Meena, Medical officer, Department of Ophthalmology, Gandhi Medical College, Bhopal, MP, ${ }^{2}$ Dr. Unnati \\ Sharma, MS, Ophthalmolgy, GMC , Bhopal, MP, India.
}

Address for Correspondence: Dr. Vandana Meena, Email: meena.vandana@gmail.com

\begin{abstract}
Background: Early recognition of papilledema and elevated ICP is of paramount importance for ensuring restoration of vision. Papilledema, frequently occurs in the setting of increased ICP and in a variety of medical conditions, including pseudotumorcerebri, sinus thrombosis, intracerebral hemorrhage, frontal lobe neoplasms, and Chiari malformation.the primary role of imaging in the diagnosis of idiopathic intracranial hypertension (IIH) has been to exclude other conditions that can cause increased intracranial pressure (ICP) and papilledema. Material \& Methods: The present study is a non randomized prospective case series being conducted in the 50 patients with disc edema/papilledema attending OPD and referred from other departments to DEPARTMENT OF OPHTHALMOLOGY, Gandhi Medical College and associated Hamidia Hospital, Bhopal from January 2013- December 2014, All patients underwent a complete medical evaluation including careful history taking, ophthalmic examination, Investigations includes MRI Scan was done in Radiology as well neurology reference was taken from Neurosurgery department, Hamidia Hospital, G.M.C. Bhopal. Result: In radiological study ICSOL is observed in $70.58 \%$ cases followed by $11.76 \%$ cases of sinusitis followed by $5.88 \%$ case each venous thrombosis,demyelination and infarction. Conclusion: Early recognition of papilledema and elevated ICP is of paramount importance for ensuring restoration of vision. Newer advanced MR imaging techniques such as fMRI and DTI may prove useful in the future to assess the potential effects of papilledema on retinal and visual pathway integrity.
\end{abstract}

Keywords: Idiopathic Intracranial Hypertension, Cerebral Venous Thrombosis, Venous Hypertension, MRI.

\section{Introduction}

The term papilledema should be strictly reserved for optic disc edema as a result of increasedcerebral spinal fluid (CSF), which bears specific etiologic implications. The most important entity to consider in cases of increased intracranial pressure is a space occupying lesion of the brain. This is often done with diagnostic tools such as Magnetic Resonance Imaging (MRI) and/or Computerized Tomography (CT) scans in conjunction with a lumbar puncture (LP)[1]. Computerized Tomography has traditionally been the imaging study of choice because of its availability and lower cost per patient than MRI. However, MRI has emerged as the technically optimal imaging modality [1]. Over the past decade, numerous publications have emphasized the MRI findings seen in patients with increased intracranial pressure (ICP) [2-4].

Manuscript received: $23^{\text {rd }}$ Jan 2016

Reviewed: 01 ${ }^{\text {st }}$ Feb 2016

Author Corrected: $11^{\text {th }}$ Feb 2016

Accepted for Publication: $22^{\text {nd }}$ Feb 2016
Empty sellaturcica has been described as a classic sign of chronically elevated ICP [5-9]. Additionally, transverse sinus stenosis (TSS) [10,11], optic disc protrusion [12], flattening of the posterior globes [3,7], and prominence of the perioptic nerve CSF spaces [3,13-16], are also commonly reported in patients with increased ICP, particularly those with idiopathic intracranial hypertension (IIH). However, none of these signs are pathognomonic of IIH $[17,18]$, and all have even been described in presumed normal subjects [10].

Papilledema has gained increasing interest in recent yearsamong neuro-ophthalmologists as the result of several clinical studies demonstrating that it may have not only diagnosticpotential as a measure of increased ICP4-7 but also therapeuticpotential as a measure of disease severity and response toTreatment[13]. Pathogenesis of Papilledema, Because all CSF spaces communicate freely, the pressure andcomposition of the 
CSF is thought to be the same throughoutthe CNS. Consequently, researchers have based their theoriesand experiments on the assumption that the pressure in theSAS surrounding theONis the same as that in the cerebral andspinal SAS. However, this assumption has not been proved, mainly due to the difficulty in obtaining accurate pressure measurements in the SAS of the $\mathrm{ON}$ in vivo.

In the SAS of theON, CSF flows from the chiasmatic cistern through the canalicularportion and into the intraorbital portion of the $\mathrm{ON}$, aspace that becomes a cul de sac at the back of the globe [19]. In attempting to detect and diagnose papilledema asearly as possible in patients, MR imaging is becoming a

useful noninvasive method. Because MR imaging can providegross visualization of the optic globe, ON, orbits, and optic tract [20] it is an ideal tool to study the details of papilledema.This review provides a brief outline of the commonMR imaging findings of papilledema and its pathologicmechanisms.

\section{Material and Methods}

The present study is a non randomized prospective case series being conducted in the patients with disc edema/papilledema attending OPD and referred from other departments, to, DEPARTMENT OF OPHTHALMOLOGY, Gandhi Medical College and associated Hamidia Hospital, Bhopal from January 2013- December 2014.

\section{Inclusion Criteria:}

Proven case of disc edema

Proven case of papilledema

\section{Exclusion Criteria:}

Cases of pseudopapilledema

All patients underwent a complete medical evaluation including careful history taking, ophthalmic examination, complete blood count, MRI scan, and CSF analysis (including opening pressure). Ocular examination consists of visual acuity measurement with Snellen's chart, anterior segment examination using slit lamp biomicroscopy, applanation tonometry, stereoscopic fundus photography and visual fields evaluation using automated perimetry with the Humphrey 30-2 program. The degree of papilledema wasgraded using Frisen's scheme [3,4]. Visual acuity, optic disc changes, and visual field defectswere checked in all the patients during follow-up.Fundus evaluation with indirect ophthalmoscope and +90 D slit lamp examination.

In early papilledema we may get following fundus findings.

- Hyperemia of the disc

- Blurring of the disc margin

- Apparent forward protrusion of disc

- Blurring of the physiological cup

- Overfilling of the vein

In some early case of papilledema, haemorrhage and exudates may be present at some distance from the disc. Fully developed and late papilledema The physiological cup becomes partially or completely obliterated, the margin of the disc becomes definitely blurred, the surrounding retina may have grayish tinge and the vessels are seen to climb to attain the disc, the veins become engorged. Haemorrhage may appear as a linear streak on the disc or around it.

Persistent papilledema: The arteries are not any time narrowed because when the arteries exhibit narrowing atrophic changes in the disc invariably follow.

In all patients showing papilledema in fundus examination, Investigations include MRI and CT Scan were done in Radiology department as well neurology reference was taken from Neurosurgery department, Hamidia Hospital, G.M.C. Bhopal.

All pateints were evaluated of papilloedemarequired a patient to undergone urgent neuroimaging to rule out an intracranial mass or duralsinus thrombosis. Although computerised axial tomography is certainly adequate in most instances, magnetic resonance imaging is quite effective in ruling out both a mass lesion as well as a potential dural sinus thrombosis. MR angiography is done in selected cases to investigate the possibility of a dural venous sinus thrombosis, infarction, haemorhages.

Statistical Analyses: The analyses were largely descriptive, with means, standard deviations, and ranges reported for continuous variables and counts and percentages reported for categorical variables. Associations between continuous variables are described using either Pearson correlation coefficients or Spearman rank correlation coefficients, as appropriate. 


\section{Results}

Table No.- 1: Relation between causes and age group

\begin{tabular}{|c|c|c|c|c|c|c|c|c|c|c|c|c|c|}
\hline \multirow[t]{2}{*}{ Cause } & \multicolumn{2}{|c|}{$0-10$} & \multicolumn{2}{|c|}{$11-20$} & \multicolumn{2}{|c|}{$21-30$} & \multicolumn{2}{|c|}{$31-40$} & \multicolumn{2}{|c|}{$41-50$} & \multicolumn{2}{|c|}{$51-60$} & \multirow[t]{2}{*}{ Total } \\
\hline & No. & $\%$ & No. & $\%$ & No. & $\%$ & No. & $\%$ & No. & $\%$ & No. & $\%$ & \\
\hline Optic neuropathy & 1 & 0 & 4 & 0 & 2 & 0 & 3 & 0 & 1 & 0 & 0 & 0 & 11 \\
\hline Aion & 0 & 0 & 0 & 0 & 0 & 0 & 0 & 0 & 0 & 0 & 3 & 0 & 3 \\
\hline Brao & 0 & 0 & 0 & 0 & 0 & 0 & 0 & 0 & 1 & 0 & 0 & 0 & 1 \\
\hline Icsol & 0 & 0 & 4 & 0 & 4 & 0 & 4 & 0 & 0 & 0 & 0 & 0 & 12 \\
\hline Meningitis & 2 & 0 & 0 & 0 & 4 & 0 & 0 & 0 & 0 & 0 & 0 & 0 & 6 \\
\hline $\begin{array}{l}\text { Malignant } \\
\text { hypertension }\end{array}$ & 0 & 0 & 0 & 0 & 5 & 0 & 0 & 0 & 0 & 0 & 0 & 0 & 5 \\
\hline Diabetes & 0 & 0 & 0 & 0 & 0 & 0 & 0 & 0 & 1 & 0 & 0 & 0 & 1 \\
\hline $\begin{array}{l}\text { Pseudo tumor } \\
\text { cerebri }\end{array}$ & 0 & 0 & 0 & 0 & 1 & 0 & 0 & 0 & 0 & 0 & 0 & 0 & 1 \\
\hline Drug history & 1 & 0 & 1 & 0 & 0 & 0 & 0 & 0 & 2 & 0 & 0 & 0 & 4 \\
\hline Malaria & 1 & 0 & 2 & 0 & 0 & 0 & 0 & 0 & 0 & 0 & 0 & 0 & 3 \\
\hline Anaemia & 0 & 0 & 1 & 0 & 0 & 0 & 0 & 0 & 0 & 0 & 0 & 0 & 1 \\
\hline Encephalopathy & 1 & 0 & 0 & 0 & 0 & 0 & 0 & 0 & 0 & 0 & 0 & 0 & 1 \\
\hline Head injury & 0 & 0 & 0 & 0 & 0 & 0 & 1 & 0 & 0 & 0 & 0 & 0 & 1 \\
\hline Total & 6 & 12 & 12 & 24 & 16 & 32 & 8 & 16 & 5 & 10 & 3 & 6 & 50 \\
\hline
\end{tabular}

In this study most common age group affected was 21-30 years in which $32 \%$ are observed and least common age group were $51-60 \mathrm{yr}$ in which only $6 \%$ case are observed. In this study out of 50 patient $30 \%$ patient were of local cause in which $22 \%$ cases were of optic neuropathy followed by $6 \%$ cases of AION in age group of 51-60 year followed by $2 \%$ case of BRAO in age group of 41-40year. Remaining $70 \%$ patients had systemic cause in which, $24 \%$ cases of ICSOL, followed by $12 \%$ cases of meningitis, $10 \%$ cases of malignant hypertension, $8 \%$ cases of drug history, $6 \%$ cases of malaria and $2 \%$ case each of diabetes, pseudotumorcerebri, anaemia, encephalopathy and head injury.

Table 2: Radiological Finding

\begin{tabular}{|l|l|l|}
\hline Radiologicl finding & No of cases & \% of cases \\
\hline Icsol & 11 & 64.70 \\
\hline Venous thrombosis & 2 & 11.76 \\
\hline Demyelination & 1 & 5.88 \\
\hline Sinusitis & 2 & 11.78 \\
\hline Infarction & 1 & 5.88 \\
\hline Total & $\mathbf{1 7}$ & $\mathbf{1 0 0}$ \\
\hline
\end{tabular}

All pateints OF papelledema underwent MRI SCAN, in which abnormalities were found in 34\% of pateints,in which , ICSOL were observed in $70.58 \%$ cases followed by $11.78 \%$ cases of sinusitis, $11.76 \%$ cases of venous thrombosis, $5.88 \%$ cases of venous thrombosis, and $1 \%$ case of demyelination and infarction each .

\section{Discussion}

The primary role of brain imaging in papilledema is to exclude other pathologies causing intracranial hypertension. However, subtle radiologic findings suggestive of IIH have emerged with modern neuroimaging. This review provides a detailed of the imaging findings reported and discusses their possible roles in the pathophysiology and the diagnosis of papilledema. Specific neuroimaging findings may suggest long-standing IIH, including empty sella, flattening of the posterior globes, optic nerve head protrusion, distention of the optic nerve sheaths, 
tortuosity of the optic nerve, cerebellar tonsillar herniation, meningoceles, CSF leaks, and transverse venous sinus stenosis [21]. A number of studies have used imaging techniques to investigatethe anatomic changes of theONin papilledema [22,23,24]Of the many imaging techniques, MR imaging has been ofparticular interest because of its ability to provide gross visualizationof the optic globe, ON, orbits, and optic tract. Additionally,MR imaging provides higher softtissue contrast andfree section orientation capabilities compared with CT andappears to be more accurate in assessing the ON thansonography[25].

Despite these advantages, the ON has been technically difficultto image because of its small size: It is 0.4-0.6 $\mathrm{cm}$ in diameter within the orbit. T2-weighted FSE sequences withfat-suppression have been found to be optimal for visualizingthe $\mathrm{ONs}$ and perioptic CSF.[26,27] Coronal image acquisition isoptimal for visualizing the true dimensions of the $\mathrm{ON}$ andperioptic CSF relative to the surrounding sheath. The mostcommonly reported macroscopic findings in MR images ofpatients diagnosed with papilledema are the following: 1) enlargement of the ONS, 2) flattening of the posteriorsclera, 3) protrusion of the optic papilla into the globe, and 4) tortuosity of the ON[28]. While researchers have investigated the relationship betweenelevated ICP and papilledema, they have also used ocular andON abnormalities to diagnose elevated ICP. The ophthalmoscopicappearance of IIH is most often characterized byvariable.Furthermore, papilledema may be asymmetric orunilateral, and the degree of ON head swelling is poorlycorrelated with ICP [29].

In the recent William F. Hoyt Lecture of the AmericanAcademy of Ophthalmology, Dr Jonathan Trobe posited that papilledema is only a reliable indicator of chronically high ICPbecause the development of papilledema tends to lag behindthe rise in ICP. Trobe noted that fewer than $20 \%$ of patientsexamined within a few days of head trauma or ruptured aneurysmhave papilledema and only $6 \%$ of patients with chronicallyhigh ICP lack papilledema [30]. On the other hand, intracranialhypertension can occur without the presence ofpapilledema [30]. Possibly, MR imaging could assess thepresence of intracranial hypertension before the developmentof papilledema [31]. According to Hansen and Helmke [32] there is a correlation between the width of the ONS and increased ICP. A width of _5 mm in this location is considered abnormal [20]. This may occur because the
ONS is not as rigid as other intracranial meningeal structures and can thus react without volume changes of intracranial CSF spaces [31].

This may occur because the ONS is not as rigid as other intracranialmeningeal structures and can thus react without volumechanges of intracranial CSF spaces [32]. Once the diagnosis of elevated ICP is established, the appearance of the discs and the severity of papilledema are commonly used as measures of disease severity and response to therapy. However, the degree of papilledema does not predict the severity of symptoms. Increased CSF pressure might produce different disc abnormalities depending on the normal size of the ONS. Further studies [13] should lead to a better understanding of the mechanisms and augment our ability to detect papilledema on imaging and allow early intervention to maintain or restore vision. Similar study done by passi et al[33] they studied, Noninvasive imaging of the $\mathrm{ON}$ is possible by using MR imaging, with a variety of findings occurring in the setting of papilledema, including flattening of the posterior sclera, protrusion of the optic disc, widening of the ONS, and tortuosity of the ON. Early recognition of papilledema and elevated ICP is of paramount importance for ensuring restoration of vision.

Maysa et al[34] studied MRI findings of elevated intracranial pressure in cerebral venous thrombosis versus idiopathic intracranial hypertension with transverse sinus stenosisFound that on $29 \mathrm{IIH}$ patients (28 women, 19 black, median-age 28, median-body mass index, 34) had bilateral TSS. 31 CVT patients (19 women, 13 black, median-age 46, median-BMI 29) had thrombosis of the sagittal (3), sigmoid (3), cavernous (1), unilateral transverse (7), or multiple (16) sinuses or cortical veins (1). Empty/partially-empty sellae were more common in IIH (3/29 and 24/29) than in CVT patients $(1 / 31$ and 19/31) $(\mathrm{p}<0.001)$. Flattening of the globes and dilation/tortuosity of the optic nerve sheaths were more common in IIH $(20 / 29$ and 18/29) than in CVT patients $(13 / 31$ and 5/31) $(\mathrm{p}<0.04)$. Papilloedema simply means oedema of the optic disc, without reference to its underlying cause. It may be due to different pathological states, of which the most important ones are mentioned in Table I[35]. This article mainly concentrates on papilloedema due to raised intracranial pressure. In our All pateints of papilledema underwent MRI SCAN, in which abnormalities were found in $34 \%$ of pateints, in which , ICSOL were observed in $70.58 \%$ cases followed by $11.78 \%$ cases of sinusitis, $11.76 \%$ cases of venous thrombosis, $5.88 \%$ cases of venous thrombosis, and $1 \%$ 
case of demyelination and infarction each. Rohr AC et al [17] Cranial venous outflow obstruction and ONS hydrops were the most valid signs indicating $\mathrm{IH}$ with a sensitivity of $94 \%$ and $92 \%$ and a specificity of $100 \%$ and $89 \%$, respectively. Sensitivities and specificities were $56 \%$ and $97 \%$ for reduced pituitary height, $64 \%$ and $78 \%$ for flattening of the posterior sclera, $31 \%$ and $97 \%$ for widening of the superior ophthalmic veins, $33 \%$ and $100 \%$ for optic disc protrusion, $14 \%$ and $100 \%$ for optic nerve edema, and $6 \%$ and $100 \%$ for elongation of the optic nerve. At least $2 \mathrm{MR}$ imaging findings could be demonstrated in each patient but in none of the controls. The number of positive MR imaging findings correlated with CSF pressure $(\mathrm{r}=$ $0.62, \mathrm{P}=.01)$. The combination of cranial and orbital MR imaging and MRV can be highly sensitive and specific in the diagnosis of patients with IH. Causes of Optic Disc Oedema andPapilloedema [35]-

1. Increased intracranial pressure (tumour, haemorrhage, infarction, abscess, oedema, benign intracranial hypertension).

2. Inflammatory optic neuropathy (optic or retrobulbar neuritis)

3. Infiltrative optic neuropathy (sarcoidosis, leukaemia and other malignancies)

4. Optic nerve tumours (angioma, meningioma, childhood optic nerve glioma, malignant optic nerveglioma, metastatic carcinoma).

5. Compressive optic neuropathy (Grave's disease, sphenoid wing meningioma).

6. Vasculopathies (anterior ischaemic optic neuropathy, central retinal vein occlusion, malignant hypertension).

7. Intra-ocular disease (posterior uveitis, posterior scleritis).

8. Venous obstruction (due to space occupying lesions in the orbit, cortico-cavernous fistula, intrathoracic venous obstruction as by neoplasms, aneurysm of aorta).

9. Conditions associated with a massive increase in the protein content of CSF (e.g., some cases ofGuillainBarre syndrome and spinal tumours).

10. Pseudopapilloedema (optic disc drusen, hyperopia and other anomalies).
Neuroimaging is helpful in excluding other causes of raised intracranial tension like space-occupying lesions. Venous sinus thrombosis can present with severe headache from intracranial hypertension secondary to impairment of CSF reabsorption, which can clinically mimic IIH symptoms. Magnetic resonance imaging (MRI) of the head and orbit with intravenous contrast and magnetic resonance venography (MRV) are the modalities of choice to exclude any structural lesions prior to IIH diagnosis. Several radiologic signs are suggestive of IIH; however, none of them are pathognomonic for this condition [36]. Similar to our study bidot $\mathrm{S}$ et al[21] found that Specific neuroimaging findings may suggest long-standing $\mathrm{IIH}$, including empty sella, flattening of the posterior globes, optic nerve head protrusion, distention of the optic nerve sheaths, tortuosity of the optic nerve, cerebellar tonsillar herniation, meningoceles, CSF leaks, and transverse venous sinus stenosis[21]. All pateints of papelledema underwent MRI SCAN, in which abnormalities were found in $34 \%$ of pateints, in which ICSOL were observed in $70.58 \%$ cases followed by $11.78 \%$ cases of sinusitis, $11.76 \%$ cases of venous thrombosis, $5.88 \%$ cases of venous thrombosis, and $1 \%$ case of demyelination and infarction each, Similarly Agrawal et al [35] found systemic causes are more prominent than local causes, in which ICSOL are most common among all causes.

\section{Conclusion}

Papilledema represents a serious warning sign for elevated ICP and potential vision loss in a variety of clinical settings. MR imaging may facilitate its detection and demonstrate changes of elevated ICP well before the appearance of papilledema on fundoscopic examination. Although the mechanisms causing papilledema and its associated signs are not entirely clear, the role for noninvasive imaging in this clinical condition is evident. Future advances in DTI, fMRI of the retina, and high-resolution MR imaging hold the promise of demonstrating the effects of papilledema on the visual pathway in patients.

\section{Funding: Nil \\ Conflict of interest: None. \\ Permission of IRB: Yes}

\section{References}

1.Bell RA. Economics of MRI technology.J MagnReson Imaging. 1996;1:10 25 
2. Bruce BB, Biousse V, Newman NJ. Update on idiopathic intracranial hypertension. Am J Ophthalmol. 2011 Aug;152(2):163-9. doi: 10.1016/j.ajo.2011.03.020. Epub 2011 Jun 21.

3. Agid R, Farb RI, Willinsky RA, Mikulis DJ, Tomlinson G. Idiopathic intracranial hypertension: the validity of cross-sectional neuroimaging signs. Neuroradiology. 2006;48:521-527.

4. Wall M. Idiopathic intracranial hypertension. NeurolClin. 2010;28:593-617.

5. Silbergleit R, Junck L, Gebarski SS, Hatfield MK. Idiopathic intracranial hypertension (pseudotumor cerebri): MR imaging. Radiology. 1989 Jan;170(1 Pt 1):207-9.

6. George AE. Idiopathic intracranial hypertension: pathogenesis and the role of MR imaging. Radiology. 1989 Jan;170(1 Pt 1):21-2.

7. Brodsky MC, Vaphiades M. Magnetic resonance imaging in pseudotumor cerebri. Ophthalmology. 1998 Sep;105(9):1686-93.

8. Yuh WT, Zhu M, Taoka T, Quets JP, Maley JE, Muhonen MG, Schuster ME, Kardon RH. MR imaging of pituitary morphology in idiopathic intracranial hypertension. J MagnReson Imaging. 2000;12:808-813.

9. Degnan $\mathrm{AJ}^{1}$, Levy LM. Pseudotumor cerebri: brief review of clinical syndrome and imaging findings. AJNR Am J Neuroradiol. 2011 Dec;32(11):1986-93. doi: 10.3174/ajnr.A2404. Epub 2011 Jun 16.

10. Farb RI, Vanek I, Scott JN, Mikulis DJ, Willinsky RA, Tomlinson G, terBrugge KG. Idiopathic intracranial hypertension: the prevalence and morphology of sinovenous stenosis. Neurology. 2003 May 13;60(9):1418-24.

11. Higgins $\mathrm{JN}^{1}$, Cousins $\mathrm{C}$, Owler BK, Sarkies $\mathrm{N}$, Pickard JD. Idiopathic intracranial hypertension: 12 cases treated by venous sinus stenting. J Neurol Neurosurg Psychiatry. 2003 Dec;74(12):1662-6.

12. Jinkins JR, Athale S, Xiong L, Yuh WT, Rothman MI, Nguyen PT. MR of optic papilla protrusion in patients with high intracranial pressure. AJNR Am J Neuroradiol. 1996;17:665-

13. Gass A, Barker GJ, Riordan-Eva P, MacManus D, Sanders M, Tofts PS, McDonald WI, Moseley IF, Miller DH. MRI of the optic nerve in benign intracranial

hypertension. Neuroradiology. 1996;38:769-773.

14. Watanabe A, Kinouchi H, Horikoshi T, Uchida $\mathrm{M}$, Ishigame $\mathrm{K}$. Effect of intracranial pressure on the diameter of the optic nerve sheath. J Neurosurg. 2008 Aug;109(2):255-8. doi: 10.3171/JNS/2008/109/8/0255.

15. Degnan AJ, Levy LM. Narrowing of Meckel's cave and cavernous sinus and enlargement of the optic nerve sheath in Pseudotumor Cerebri. J Comput Assist Tomogr. 2011 Mar-Apr;35(2):308-12. doi: 10.1097/RCT.0b013e31820d7a70.

16. Shofty B, Ben-Sira L, Constantini S, Freedman S, Kesler A. Optic nerve sheath diameter on MR Imaging: establishment of norms and comparison of pediatric patients with idiopathic intracranial hypertension with healthy controls. AJNR Am J Neuroradiol. 2012;33:366-369.

17. Rohr AC, Riedel C, Fruehauf MC, van Baalen A, Bartsch T, Hedderich J, Alfke K, Doerner L, Jansen O. MR imaging findings in patients with secondary intracranial hypertension. AJNR Am J Neuroradiol. 2011 Jun-Jul;32(6):1021-9. doi: 10.3174/ajnr.A2463. Epub 2011 Apr 21.

18. Biousse V, Ameri A, Bousser MG. Isolated intracranial hypertension as the only sign of cerebral venous thrombosis. Neurology. 1999 Oct 22;53(7):1537-42.

19. Killer HE, Jaggi GP, Miller NR. Papilledema revisited: is its pathophysiology really understood? Clin Experiment Ophthalmol. 2009 Jul;37(5):444-7. doi: 10.1111/j.1442-9071.2009.02059.x.

20, Seitz J, Held P, Strotzer M, et al. Magnetic resonance imaging in patients diagnosed with papilledema: a comparison of 6 different high-

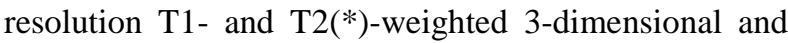
2-dimensional sequences. J Neuroimaging 2002;12:164-71

21. Bidot S, Saindane AM, Peragallo JH, Bruce BB, Newman NJ, Biousse V. Brain Imaging in Idiopathic Intracranial Hypertension. J Neuroophthalmol. 2015 Dec;35(4):400-11. doi: 10.1097/WNO.0000000000000303.

22. Digre KB, Nakamoto BK, Warner JE, Langeberg WJ, Baggaley SK, Katz BJ. A comparison of idiopathic intracranial hypertension with and without papilledema. Headache. 2009 Feb;49(2):185-93. doi: 10.1111/j.15264610.2008.01324.x. 
23.Mashima Y, Oshitari K, Imamura Y, et al. Highresolution magnetic resonance imaging of the intraorbital optic nerve and subarachnoid space in patients with papilledema and optic atrophy. Arch Ophthalmol1996;114:1197-203.

24.Gibby WA, Cohen MS, Goldberg HI, et al. Pseudotumorcerebri: CT findings and correlation with vision loss. AJR Am J Roentgenol1993;160:143- 46

25.Lagre`ze WA, Lazzaro A, Weigel $M$, et al. Morphometry of the retrobulbarhumanoptic nerve: comparison between conventional sonography and ultrafast magnetic resonance sequences. Invest Ophthalmol Vis Sci2007;48:1913-17

26. Kimberly HH, Noble VE. Using MRI of the optic nerve sheath to detect elevated intracranial pressure. Crit Care. 2008;12 (5):181. doi: 10.1186/cc7008. Epub 2008 Sep 24.

27. Geeraerts T, Newcombe VF, Coles JP, Abate MG, Perkes IE, Hutchinson PJ, Outtrim JG, Chatfield DA, Menon DK. Use of T2-weighted magnetic resonance imaging of the optic nerve sheath to detect raised intracranial pressure. Crit Care. 2008;12(5):R114. doi: 10.1186/cc7006. Epub 2008 Sep 11.

28. Eliseeva NM, Serova NK, Arutiunov NV. [Magnetic resonance imaging of the orbital portion of the optic nerve at different stages of papilledema]. Vestn Oftalmol. 2005 Nov-Dec;121(6):5-9.
29. Mathew NT, Ravishankar K, Sanin LC. Coexistence of migraine and idiopathic intracranial hypertension without papilledema. Neurology 1996;46:1226-30

30. Trobe JD. Papilledema: the vexing issues. J Neuroophthalmol. 2011 Jun;31(2):175-86. doi: 10.1097/WNO.0b013e31821a8b0b.

31. Winner P, Bello L. Idiopathic intracranial hypertension in a young child without visual symptoms or signs. Headache. 1996 Oct;36(9):574-6.

32. Hansen HC, Helmke K. Validation of the optic nerve sheath response to changing cerebrospinal fluid pressure: ultrasound findings during intrathecal infusion tests. J Neurosurg. 1997 Jul;87(1):34-40.

33. Passi N, Degnan AJ, Levy LM. MR imaging of papilledema and visual pathways: effects of increased intracranial pressure and pathophysiologic mechanisms. AJNR Am J Neuroradiol. 2013 May;34(5):919-24. doi: 10.3174/ajnr.A3022. Epub 2012 Mar 15.

34. Maysa A Ridha, ${ }^{a}$ Amit M SaindaneMRI findings of elevated intracranial pressure in cerebral venous thrombosis versus idiopathic intracranial hypertension with transverse sinus stenosis Neuroophthalmology. $2013 \quad$ Feb $\quad 1 ; \quad 37(1)$ : $1-$ 6.doi: $10.3109 / 01658107.2012 .738759$

35. AK Agarwal*, PushpaYadav Papilledema (choked disc) Journal, Indian Academy of Clinical Medicine Vol. 1, No. 3 _ October-December 2000

36. Julayanont $P$, Karukote $A^{2}$, Ruthirago $D^{1}$, Panikkath $\mathrm{D}^{3}$, Panikkath $\mathrm{R}^{3}$. Idiopathic intracranial hypertension: ongoing clinical challenges and future prospects. J Pain Res. 2016 Feb 19;9:87-99. doi: 10.2147/JPR.S60633. eCollection

2016.

\section{How to cite this article?}

Meena V, Sharma U Study of radiological findings in papilledema. Int J Med Res Rev 2016;4(2):254-260. doi: 10.17511/ijmrr.2016.i02.021 